IP Periodica Polytechnica

Transportation Engineering

44(4), pp. 235-243, 2016

DOI: $10.3311 /$ PPtr.9224

Creative Commons Attribution (i)

\title{
The Effect of EMU Driver Operating Time on Professional Psychological Quality
}

\author{
Hong Zhou ${ }^{1 *}$, Long $\mathrm{Ye}^{2}$, Ming Guo ${ }^{3}$, Daqing Gong ${ }^{4}$
}

Received 23 March 2016; accepted 18 August 2016

\begin{abstract}
Purpose: EMU driver operation time is an important part of the locomotive crew system. To ensure the safe, efficient and accurate operation of the EMU (Electric Multiple Unit), drivers not only need to have good physical and mental health but also must be able to work under the conditions of a scientific, reasonable and humanized organization.
\end{abstract}

Design/methodology/approach: To effectively analyze the actual job of an EMU driver and to avoid impacting the normal work of the drivers, we selected some of the items from the professional mentality test project, which we had found had resulted in short test times and high test reliability and validity.

Findings: With a single-driver continuous value multiplied by a time of less than two hours, there were no significant differences; multiplied by more than 4 hours, there was a significant difference in psychological quality; specifically, the multiplied career mental quality level decreased significantly. The EMU single continuous value multiplied by driving time driver should not be more than four hours to receive the full benefit. Originality/value: Based on the different operating times, this study compared the organization of different jobs in different situations. The negative impact of psychological load on EMU driver labor intensity varied.

\section{Keywords}

EMU Drivers, Vocational Psychological Quality, Mental Workload, Labor Intensity

\footnotetext{
'School of Economics \& Management Beijing Jiaotong University, Beijing, China

"Corresponding author, e-mail: bjtuahong@163.com
}

\section{Introduction}

There is a great difference between the EMU and existing railways in technological installations, postal transportation commands and labor organization management modes. EMU security, stability, and drive times not only put forward strict technical standards for a variety of railway construction hardware facilities but also need even stricter requirements for the process of developing various software facilities, including those used by railway operation personnel. Related to the safety of railway transportation, the driver is the most important factor, and he is the core subsystem in driving safety throughout the system. Meanwhile, the psychological qualities of the driver directly determine the safe operation of the train, strengthening and ensuring the safety of railway traffic management. Thus, the driver has an irreplaceable function as a key link in railway transportation.

EMU driver operation time is an important part of the locomotive crew system. With the changes in the EMU's hardware facilities and running environment came new EMU operations, including a new driver working mode, locomotive crew working system and labor organization management mode. Moreover, driver operation time also changes. To ensure the safe, efficient and accurate operation of the EMU, drivers not only need to have good physical and mental health but also must be able to work under the conditions of a scientific, reasonable and humanized organization.

Thus, the research questions are: how should EMU drivers' psychological status be evaluated in a scientific, reasonable and effective manner, and how should the relationship between the driver's psychological status and their operating time be determined given different operating and organizational conditions. This paper develops the vocational psychology diathesis quicktest macro of EMU drivers to test the EMU drivers in the Beijing, Shenyang and Shanghai railway bureaus to determine the effects of driver operating time on professional psychological quality.

\section{Literature Review}

The different characteristics of different positions across varying fields of work usually determine the psychological understanding of those positions. Usually there are two aspects 
to this determination. Scholars believe psychological qualities relate specifically to an individual's performance of his or her professional activities. However, professional qualities should also be considered, as they are the basic psychological quality that individuals must have to complete professional activities. As a result, professional psychological qualities are the basic psychological qualities required by individuals to engage in a specific occupation; these qualities are the basis of corresponding future vocational education (Gasparik, 2015).

However, with today's progress and development, the simple evaluation of labor intensity based on physical exertion cannot meet societal requirements. People now pay more attention to mental health, especially to improving the psychological load related to labor intensity. In particular, the physical labor is many professions is limited, and the psychological load generated by environmental pressure is greater. Therefore, measurement of labor intensity in terms of mental workload is very necessary.

Mental workload is one of the most widely invoked concepts in ergonomics research and practice (Flemisch and Onken, 2002; Loft et al., 2007; Parasuraman and Hancock, 2001; Tsang and Vidulich, 2006; Wickens, 2014). The number of hits in the Ergo-Abs database resulting from a decade-by-decade search for the terms 'mental workload' and 'physical workload' has increased. This increase no doubt partly reflects the growing coverage of the database in recent years, as evidenced by equivalent searches for 'physical workload'. Nevertheless, the relative decade-on-decade increase in hits for mental workload in the 2000s suggests more recent prominence for 'mental workload', which has increased by $36 \%$, and 'physical workload', which has increased by $17 \%$.

A cursory review of these search results indicates that the focus in the 1980s was much more on measuring mental workload, whereas the 1990s saw a shift towards theoretical developments and modeling efforts. The research in the 1990s was also concerned with the proliferation of automation, and a significant body of work was directed at the emergence of more advanced physiological metrics of workload. Finally, the first decade of the twenty-first century has seen more examples of mental workload applications coming to the fore. Thus, the general evolution of research in mental workload has progressed from attempting to measure it to attempting to define it to finding its real-world applications.

Some scholars have studied the labor intensity of workers in all sectors, in addition to related factors such as labor intensity, working environment, psychological adaptability, mental load, etc. They also focus on the work quality of workers and how to minimize problems with staff mental health. The World Health Organization (WHO) assesses the mental workload of labor intensity using neurobehavioral core testing; they have selected a number of different techniques, including three functional indicators, visual motor reaction time, flashlight blending frequency and reading ability, with emotion, attention, reaction speed, listening and memory, manual operation sensitivity, speed perception, visual perception, motion stability and nine other mental fatigue test subjects.

In 1935, an American study of commercial motor vehicle driving time and traffic safety evaluated drivers' irritability, blinking frequency, nap times, attention, reaction times and other variables. They formed a precise, scientific and comprehensive system for evaluating train driver fatigue based on the system detection and supervision processes used in automobile manufacturers' manufacturing processes.

A wide range of operations such as transport, healthcare, mining, manufacturing and emergency services utilize shift work. The general relationship between hours of work, sleep, fatigue and safety is well documented (Mitler, 1988). Germany, Japan, France, Austria, the United States, Russia and other countries have studied and measured railway drivers' labor intensity, selective reaction time, heart rate, skin resistance and sensitivity and flicker fusion rate in monotonous work at the preparation and emergency action levels, using Russia's Kharkov National Railway Engineering College psychological diagnostic laboratory for railway drivers, by measuring braking capability before and after an emergency. Different studies have also assessed the degree of preparation for emergency action and the ability of the central nervous system to restore function after fatigue.

Driving a train appears to be a primarily psychological job. The train driver's job includes long periods of driving and requires the ability to remain attentive and to recognize signals and specific stimuli for long periods (Cabon, 1993; Sussman and Coplen, 2000). It is known to be more difficult to maintain attention in monotonous situations than under more cognitively demanding conditions (Langner and Eickhoff, 2013; Warm et al., 2008). Thus, a train driver's job appears to have specific psychological and cognitive requirements.

When a train driver does not meet the psychological and cognitive requirements of his work, his impaired functioning may lead to errors or mistakes, eventually leading to accidents (e.g., passing red signals, derailing or causing collisions) (Edkins and Pollock, 1997; Kecklund, 1999). However, if the psychological and cognitive requirements are proven to be highly demanding and safety-sensitive, these factors should also be included in the (medical) screening of train drivers. These psychological demands (stressors) create short-term loads or effects on workers, i.e., they create temporary reactions as a result of the work (Dormolen, 1990; van Veldhoven and Sluiter, 2009). A short-term load can be described in terms of emotional load, mental load, short-term stress, short-term fatigue/ sleepiness and decreased vigilance /attention. The degree of recovery determines whether the employee has the same work potential the next day compared with the day before or whether the short-term load will lead to adverse long-term (health) effects (van Veldhoven and Sluiter, 2009). The combination 
of psychological work characteristics and psychological load determines given psychological and cognitive requirements.

For the psychological burden of labor intensity, in addition to taking measures to ease tensions over the work with a specific focus on the mental qualities required for the work, it is possible in a number of ways to improve the usefulness of health practitioners when tension or psychological fatigue can maintain or increase the professional adaptability of workers in labor-intense positions. Therefore, investigation of the psychological burden of labor intensity, specifically the relations between various bodily measurements, can allow for the creation of standards to judge physical and psychological suitability for various occupations, which is a necessary step for improving and enhancing worker quality.

However, with the continuous improvement and development of railway operating conditions, scholars have launched studies of the effect of psychological burden on labor intensity, based on psychological evaluations of load labor intensity. In these cases, labor intensity is based on psychological evaluation loads including emotion, attention, reaction speed, listening and memory, manual sensitivity, speed of perception, visual perception, movement stability, heart rate variability, and flicker fusion rate.

With the opening of the first EMU passenger line, the locomotive crews faced a changing driving environment, and the drivers' psychological, physiological indicators and labor intensity tracking were gradually put on the agenda. However, once the EMU line had been opened for a short time, and the drivers' smaller-scale impacts were being observed, the research on their occupational health and labor intensity was found to be inadequate, for instance, regarding the relationship between EMU driver working time and psychological quality. Systems for the EMU drivers as well as scientifically applicable labor organization and management programs are imminent.

We organize this paper as follows: in the following section, we introduce the test program. In Section 4, we present the data analysis with SPSS (Statistical Product and Service Solutions) mathematical software, and in Section 5, we present the correlations and the mediation effects. Finally, we conclude the study.

\section{Data Acquisition and Test}

\subsection{Test program}

Our psychological quality evaluation system for train drivers required lengthy exploration and research. Learning from the early explorations of foreign train drivers' experiences and evaluations of their psychological quality, we conducted research on the basis of the actual conditions of China's railways. We established the SCL-90, job stability tests, cartel personality tests, learning ability tests, instantaneous memory tests, and mental focus quality assessments based primarily on the results of test data analysis and data processing. We also used multivariate statistical methods and mathematical software for statistical analysis, establishing an evaluation index of locomotive drivers (the Chinese locomotive drivers' norm). ("Locomotive crew physiological and psychological evaluation and quality standards," 1990-1994). Following on our efforts, we developed a pen-and-paper equipment evaluation and psychological quality evaluation model.

At the beginning of 2005, the Ministry of Railway Transport, the Ministry of Equipment and the individual personnel service centers began jointly selecting EMU drivers. The project leader was responsible for psychological quality testing during the project. The project team comprised high-speed train drivers from abroad who were chosen based on their experience, combined with previous research results; based on these two factors, the team developed driver EMU psychological quality evaluation and selection criteria.

\subsection{Selecting the test object}

We tested EMU driver continuous operation times of longer than four hours in our representative sample of three railway bureaus: in Shanghai, EMU drivers operated continuously for longer than four hours; in Shenyang, continuous driver operation time was up to 4 hours; and in Beijing, the single continuous operating time was less than two hours. A total of three sets of 77 EMU drivers were tested by excel software: 29 EMU drivers from the Beijing Railway Bureau, 15 EMU drivers from the Shanghai Railway Bureau, and 33 EMU drivers from the Shenyang Railway Bureau, as shown in Fig. 1.

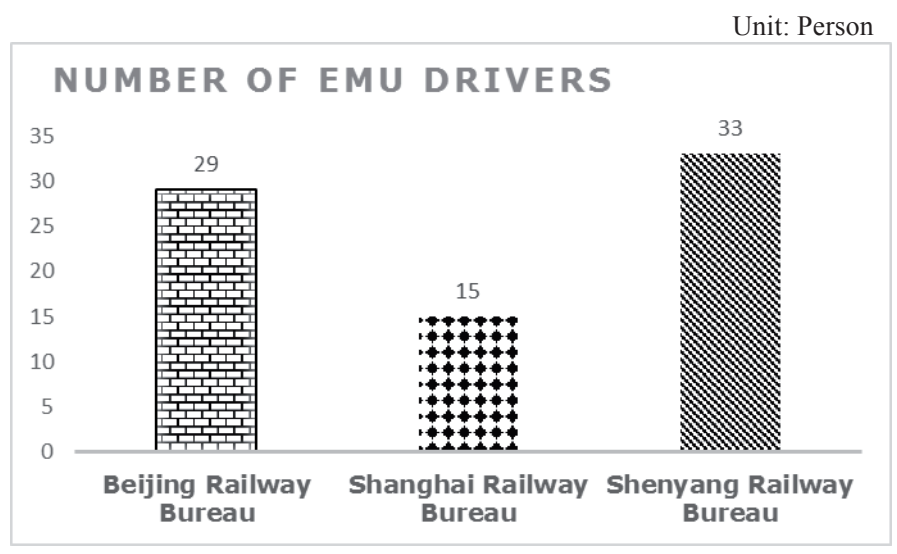

Fig. 1 Summary of the labor intensity of mental load

We analyzed the 77 randomly selected Railway Bureau EMU drivers by age and found more drivers in the first and third groups than in the second group. The second group was ages 31-40 years old, and in this survey, 10 EMU drivers from the Shanghai Railway Bureau were in this group: 24 EMU drivers from the Beijing Railway Bureau, and 15 EMU drivers from the Shenyang Railway Bureau, for a total was 49 drivers, who accounted for $63.6 \%$ of the total. Likely owing to the field tests and the EMU drivers in different age groups being in different crossroad arrangements, there were no EMU drivers in the Beijing Railway Bureau who were older than 40 years, as shown in Fig. 2. 
Unit: Person

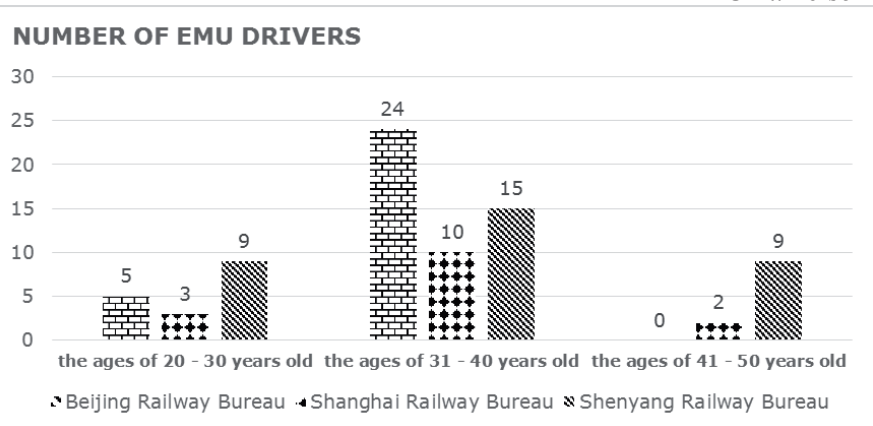

Fig. 2 Mental load of the labor intensity distribution by age

\subsection{Type of the conducted tests}

To effectively analyze the actual job of an EMU driver and to avoid impacting the normal work of the drivers, we did not use the nine-item EMU driver selection test. Instead, we selected some of the items from the professional mentality test project, which we had found had resulted in short test times and high test reliability and validity. Including attention allocation and transfer, complex reaction, learning ability, instantaneous memory, and speed tests, we derived a predictive EMU driver professional mentality rapid test system and a driver-based psychological load labor strength test (see Table 1).

Table 1 Correlation results for the psychological evaluations

\begin{tabular}{lll}
\hline Professional Psychological Quality Index & Test Project \\
\hline & Ability to judge and react & $\begin{array}{l}\text { Complex reaction test } \\
\text { Speed prediction test }\end{array}$ \\
\cline { 2 - 3 } Vocational & Learning ability & Learning ability test \\
\cline { 2 - 3 } adaptability & Instantaneous memory & Instantaneous memory \\
& capacity & capacity test \\
\cline { 2 - 3 } & The ability to focus attention & Attention allocation and \\
& allocation and transfer & transfer test \\
\hline
\end{tabular}

\subsubsection{Attention allocation and transfer test}

This test aims to study the EMU driver in actual sustained attention allocation and transfer. In this test, the subjects' completion times determine their attention to quality. Note that the findings with more extensive ranges of subjects are more stable and concentrated, and they can be quickly transferred and assigned correctly (Fig. 3).

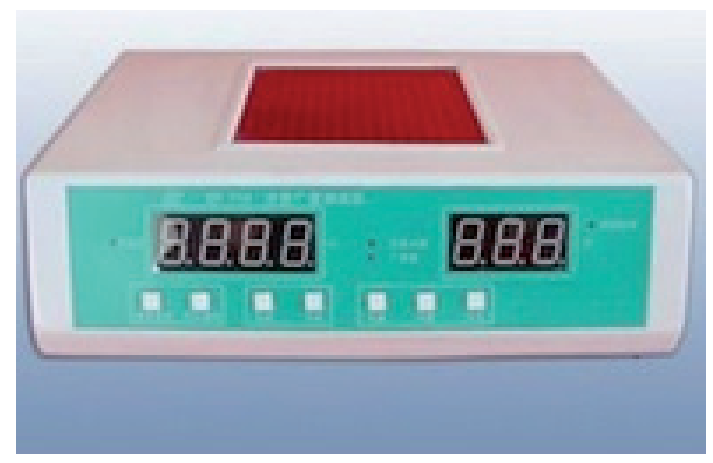

Fig. 3 Attention allocation and transfer test plan

\subsubsection{Complex reaction test}

This test aims to evaluate a driver at regular intervals using continuous displays of multiple random visual stimulation signals and auditory stimulation signals, specifically, to assess how drivers select a signal and their rates of correct responses, which entails assessing their vision and hearing and their capacities for identifying, judging and selection. Their reaction times and correct response rates were used as their evaluations. Figure 4 shows the test.

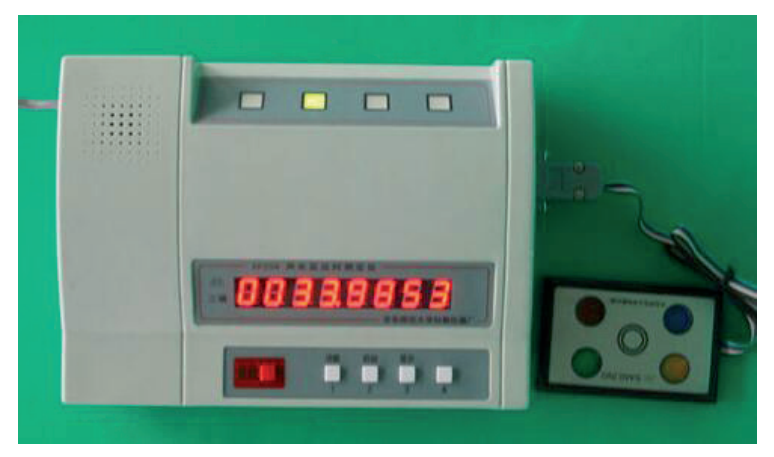

Fig. 4 Complex reaction test plan

\subsubsection{Learning ability test}

In the learning ability test, the subjects saw 10 special symbols, each corresponding to the numbers 0 through 9 ; the numbers had to be matched to the corresponding figures in the boxes below the figures. The total number of responses and the correct response rate within the specified time were used for the drivers' evaluations. The test chart is shown in Fig. 5.

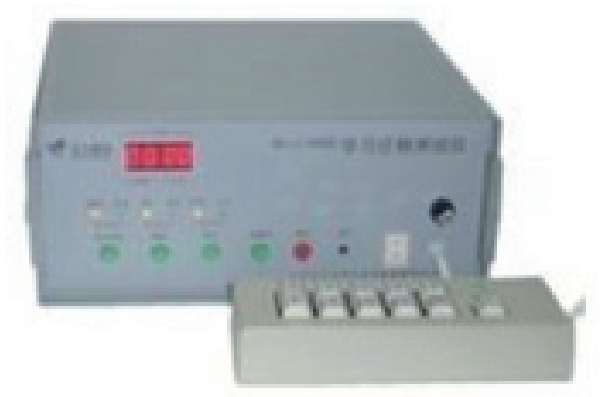

Fig. 5 Learning test pattern

\subsubsection{Instantaneous memory capacity test}

For this test, subjects are required, without using other means, to remember the numbers that are presented and then to input them, as shown in Fig. 6.

\subsubsection{Speed prediction test}

Speed prediction refers to predicting the arrival time of an object at a certain position within a certain period of time given its velocity and its original location. The aim is to study the relationship between accurate speed predictions and other major factors. The test is presented in Fig. 7, and there was a very close tie between the EMU drivers' work ability and their speed predictions. 


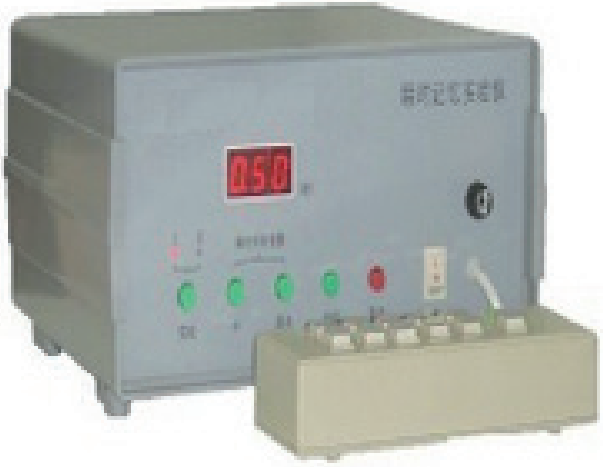

Fig. 6 Instantaneous memory capacity test pattern

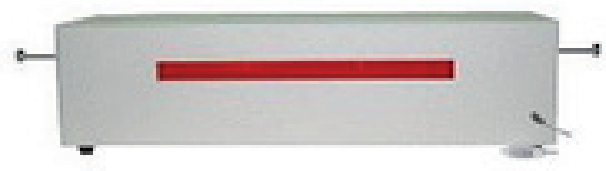

Fig. 7 Velocity prediction test pattern

\section{Data Analysis}

\subsection{Overall test data analysis}

To study the psychological burden on EMU drivers using the rapid evaluation tests in this study, a total of 77 EMU drivers from the Beijing, Shanghai, and Shenyang railway bureaus were tested before and after they drove; their professional mentality test scores were significantly different between the two time points, the details are:

IN ATT: take attention allocation and transfer of the test;

OUT ATT: return ride attention allocation and transfer test;

IN CR: multiplication of complex reaction test;

OUT CR: retreat multiply complex reaction test;

IN LE: the learning ability test ride;

OUT LE: take back learning ability test;

IN IM: an instant memory test ride;

OUT IM: return ride instant memory test;

IN VP: the forecast by speed test;

OUT VP: return ride forecast by speed test;

IN TO: total ride results;

OUT TO: take back a total score.

The results of the data analysis are presented in the following table.

Table 2 Significant differences in the EMU drivers' professional psychological test results

\begin{tabular}{llllll}
\hline & $\begin{array}{l}\text { OUT ATT } \\
\text {-IN ATT }\end{array}$ & $\begin{array}{l}\text { OUT CR } \\
\text {-IN CR }\end{array}$ & $\begin{array}{l}\text { OUT LE } \\
\text {-IN LE }\end{array}$ & $\begin{array}{l}\text { OUT IM } \\
\text {-IN IM }\end{array}$ & $\begin{array}{l}\text { OUT VP } \\
\text {-IN VP }\end{array}$ \\
\hline $\mathrm{Z}$ & $-.844 \mathrm{a}$ & $-.059 \mathrm{a}$ & $-1.875 \mathrm{a}$ & $-.300 \mathrm{~b}$ & $.000 \mathrm{c}$ \\
\hline $\begin{array}{l}\text { Asymptotic } \\
\text { significance } \\
\text { (double side) }\end{array}$ & .398 & .953 & .061 & .764 & 1.000 \\
\hline
\end{tabular}

The data analysis showed no significant differences in the five test scores among the 77 EMU drivers. In the individual and total scores, the instant memory test scores for In ATT were slightly lower than those for OUT ATT, and the remaining four test scores were higher than the OUT ATT scores. The results showed an overall decline in the professional mentality of the 77 EMU drivers that was influenced by psychological load in a single continuous operation, but the effect was not obvious, and the drivers' overall labor intensity appeared to indicate a moderate mental load.

Table 3 Descriptive statistics of the EMU drivers' professional psychological test results

\begin{tabular}{lclllll}
\hline Project & N & Minimum & Maximum & Mean & $\begin{array}{l}\text { Standard } \\
\text { Deviation }\end{array}$ & Variance \\
\hline IN ATT & 77 & 3.00 & 11.00 & 8.2727 & 1.42012 & 2.017 \\
OUT ATT & 77 & 2.00 & 11.00 & 8.1039 & 1.53541 & 2.357 \\
IN CR & 77 & -4.60 & 9.00 & 5.8545 & 2.29453 & 5.265 \\
OUT CR & 77 & -7.20 & 8.40 & 5.7429 & 2.62936 & 6.914 \\
IN LE & 77 & 6.00 & 16.00 & 9.7792 & 1.76682 & 3.122 \\
OUT LE & 77 & 4.00 & 17.00 & 9.3117 & 2.29565 & 5.270 \\
IN IM & 77 & 5.00 & 19.00 & 13.1818 & 3.15698 & 9.967 \\
OUT IM & 77 & 3.00 & 19.00 & 13.1948 & 3.61298 & 13.054 \\
IN VP & 77 & -1.20 & 9.80 & 6.8987 & 1.94114 & 3.768 \\
OUT VP & 77 & -2.00 & 9.80 & 6.6844 & 2.40477 & 5.783 \\
\hline
\end{tabular}

Negative variable means its value is less than the average of EMU drivers (the same, below).

\subsection{The comparative analysis of different job organization}

We continued to study the differing mental loads of the EMU drivers, which affected their working times and occupational psychological quality, and there were significant differences in their occupational psychological quality test scores. The analysis results for the different professional psychological quality tests for both single and double locomotive EMU drivers are presented in the following table:

Table 4 Significant differences in the Beijing EMU drivers' professional psychological test results

\begin{tabular}{lllllll}
\hline & OUT TO & OUT & OUT & OUT & OUT & OUT \\
& -IN TO & $\begin{array}{l}\text { ATT } \\
\text {-IN ATT }\end{array}$ & CR & LE & IM & VP \\
& $-1.310 \mathrm{a}$ & $-1.496 \mathrm{a}$ & $-1.277 \mathrm{~b}$ & $-1.385 \mathrm{~b}$ & $-2.240 \mathrm{~b}$ & $-.024 \mathrm{a}$ \\
\hline $\mathrm{Z}$ & & & & & & \\
\hline $\begin{array}{l}\text { Asymptotic } \\
\text { significance } \\
\text { (double side) }\end{array}$ & .190 & .135 & .202 & .166 & .025 & .981 \\
\hline
\end{tabular}


The data analysis showed no significant differences in total score, attention allocation (In ATT), complex reactions, learning ability, or speed predications among the professional psychological quality rapid tests. Among the 29 EMU drivers in the Beijing Railway Bureau, there were significant differences in their instantaneous memory test scores. In the individual and total scale scores, the average instant memory test scores for In ATT were significantly lower than those for Out. The complex reaction and learning ability test scores were also lower than the average for Out ATT, and the attention distribution and speed prediction scores were higher than the average Out ATT scores.

Table 5 Descriptive statistics for the Beijing EMU drivers' professional psychological test results

\begin{tabular}{lclllll}
\hline Project & N & Minimum & Maximum & Mean & $\begin{array}{l}\text { Standard } \\
\text { Deviation }\end{array}$ & Variance \\
\hline IN ATT & 29 & 6.00 & 10.00 & 8.5862 & 1.08619 & 1.180 \\
OUT ATT & 29 & 2.00 & 10.00 & 8.1379 & 1.66313 & 2.766 \\
IN CR & 29 & 1.40 & 9.00 & 5.8897 & 1.89102 & 3.576 \\
OUT CR & 29 & -1.20 & 8.40 & 6.0483 & 2.46788 & 6.090 \\
IN LE & 29 & 6.00 & 15.00 & 9.9655 & 2.02630 & 4.106 \\
OUT LE & 29 & 6.00 & 14.00 & 10.3793 & 1.65645 & 2.744 \\
IN IM & 29 & 6.00 & 19.00 & 12.6897 & 3.14079 & 9.865 \\
OUT IM & 29 & 4.00 & 19.00 & 13.8966 & 3.42621 & 11.739 \\
IN VP & 29 & -1.20 & 9.80 & 6.6069 & 2.38296 & 5.679 \\
OUT VP & 29 & -2.00 & 9.40 & 6.1690 & 2.95431 & 8.728 \\
IN TO & 29 & 34.20 & 52.20 & 43.7379 & 4.77796 & 22.829 \\
OUT TO & 29 & 19.30 & 55.40 & 44.6310 & 7.70051 & 59.298 \\
\hline
\end{tabular}

The results showed that for the 29 EMU drivers in the Beijing Railway Bureau, their overall professional mentality scores, factoring in psychological load in a single continuous operation, improved by a small margin; for example, their instantaneous memory test scores improved significantly. Among the EMU drivers, after two hours of driving operation, dispatcher communication, recording schedule commands, complex reactions, transient memory, and learning ability all improved, including significant improvement in transient memory. Attention allocation and the predictive power of the transfers of power and speed showed slight declines, suggesting that the 27 Beijing Railway Bureau EMU drivers experienced less of an overall mental load, and thus reduced labor intensity.
Table 6 Significant differences in the Shenyang EMU drivers' professional psychological test results

\begin{tabular}{lllllll}
\hline & OUT TO & OUT & OUT & OUT & OUT & OUT \\
& -IN TO & $\begin{array}{l}\text { ATT } \\
\text {-IN ATT }\end{array}$ & CR & LE & IM & VP \\
& $-2.068 \mathrm{a}$ & $-.198 \mathrm{a}$ & $-1.796 \mathrm{~b}$ & $-3.049 \mathrm{~b}$ & $-1.235 \mathrm{~b}$ & $-.197 \mathrm{a}$ \\
\hline $\mathrm{Z}$ & & & & & & \\
\hline $\begin{array}{l}\text { Asymptotic } \\
\text { significance } \\
\text { (double side) }\end{array}$ & .039 & .843 & .072 & .002 & .217 & .844 \\
\hline
\end{tabular}

Table 7 Descriptive statistics for the Shenyang EMU drivers' professional psychological test results

\begin{tabular}{lccllll}
\hline Project & $\mathrm{N}$ & Minimum & Maximum & Mean & $\begin{array}{l}\text { Standard } \\
\text { Deviation }\end{array}$ & Variance \\
\hline IN ATT & 33 & 3.00 & 10.00 & 7.7576 & 1.56186 & 2.439 \\
OUT ATT & 33 & 5.00 & 10.00 & 7.8485 & 1.41689 & 2.008 \\
IN CR & 33 & -4.60 & 8.60 & 5.9273 & 2.64377 & 6.990 \\
OUT CR & 33 & -7.20 & 7.80 & 5.3758 & 2.78647 & 7.764 \\
IN LE & 33 & 7.00 & 12.00 & 9.4242 & 1.32359 & 1.752 \\
OUT LE & 33 & 4.00 & 14.00 & 8.2121 & 2.05787 & 4.235 \\
IN IM & 33 & 6.00 & 19.00 & 13.4545 & 2.95900 & 8.756 \\
OUT IM & 33 & 3.00 & 19.00 & 13.0000 & 2.79508 & 7.813 \\
IN VP & 33 & 2.80 & 9.20 & 7.0970 & 1.51089 & 2.283 \\
OUT VP & 33 & -1.00 & 9.80 & 7.0121 & 2.23939 & 5.015 \\
IN TO & 33 & 33.60 & 58.80 & 43.6606 & 5.87569 & 34.524 \\
OUT TO & 33 & 27.80 & 55.20 & 41.4485 & 5.59867 & 31.345 \\
\hline
\end{tabular}

The above data analysis shows that there was an overall significant decline in professional mentality influenced by psychological load in a single continuous operation among the 33 Shenyang Railway Bureau EMU drivers; their learning ability test scores decreased significantly. The drivers' complex reactions, instantaneous memory, learning ability, and ability to predict when speed had all decreased significantly. EMU driving for four hours was closely related to high attention; thus, attention allocation and transfer ability increased slightly among the 33 Shenyang Railway Bureau EMU drivers based on the higher overall labor intensity of their psychological loads.

Table 8 Significant differences in the Shanghai EMU drivers' professional psychological test results

\begin{tabular}{lllllll}
\hline & OUT TO & OUT & OUT & OUT & OUT & OUT \\
& -IN TO & ATT & CR & LE & IM & VP \\
& & -IN ATT & -IN CR & -IN LE & -IN IM & -IN VP \\
\hline $\mathrm{Z}$ & $-.511 \mathrm{a}$ & $-.905 \mathrm{a}$ & $-.910 \mathrm{~b}$ & $-1.524 \mathrm{a}$ & $-.670 \mathrm{a}$ & $-.199 \mathrm{a}$ \\
\hline $\begin{array}{l}\text { Asymptotic } \\
\text { significance } \\
\text { (double side) }\end{array}$ & .609 & .366 & .363 & .128 & .503 & .842 \\
\hline
\end{tabular}


Table 9 Descriptive statistics for the Shanghai EMU drivers' professional psychological test results

\begin{tabular}{lclllll}
\hline Project & N & Minimum & Maximum & Mean & $\begin{array}{l}\text { Standard } \\
\text { Deviation }\end{array}$ & Variance \\
\hline IN ATT & 15 & 6.00 & 11.00 & 8.8000 & 1.37321 & 1.886 \\
OUT ATT & 15 & 5.00 & 11.00 & 8.6000 & 1.50238 & 2.257 \\
IN CR & 15 & -.20 & 8.60 & 5.6267 & 2.31993 & 5.382 \\
OUT CR & 15 & -2.00 & 8.40 & 5.9600 & 2.65352 & 7.041 \\
IN LE & 15 & 7.00 & 16.00 & 10.2000 & 2.04241 & 4.171 \\
OUT LE & 15 & 5.00 & 17.00 & 9.6667 & 2.84521 & 8.095 \\
IN IM & 15 & 5.00 & 19.00 & 13.5333 & 3.68136 & 13.552 \\
OUT IM & 15 & 3.00 & 19.00 & 12.2667 & 5.24359 & 27.495 \\
IN VP & 15 & 3.20 & 9.40 & 7.0267 & 1.89566 & 3.594 \\
OUT VP & 15 & 5.00 & 9.20 & 6.9600 & 1.26084 & 1.590 \\
IN TO & 15 & 26.20 & 61.40 & 45.1867 & 8.54349 & 72.991 \\
OUT TO & 15 & 32.60 & 63.80 & 43.4533 & 9.56316 & 91.454 \\
\hline
\end{tabular}

The above data analysis shows that there was an overall significant decline in professional mentality influenced by psychological load in a single continuous operation among the 15 EMU drivers of the Shanghai Railway Bureau. Among these drivers, after driving for ten hours, their complex reactions, transient memory, learning ability, and ability to predict speed decreased. Attention allocation and transfer ability slightly increased; this finding reflects that driving as an EMU driver for ten hours during the highly focused and dual-driver duty system is closely related to physical exertion and psychological load labor intensity. This finding makes it possible to alert other EMUs of potential dangers, giving the Shanghai Railway Bureau driver group a moderate overall labor-intensity-based mental load.

\subsection{Comparative analysis by age}

This study's driver age distribution was more uniform among the 33 Shenyang Railway Bureau EMU drivers, as shown in the following table:

Table 10 Significant differences among the Shenyang EMU drivers' professional psychological test results by age

\begin{tabular}{|c|c|c|c|c|c|c|}
\hline & Group & $\begin{array}{l}\text { OUT TO } \\
\text {-IN TO }\end{array}$ & $\begin{array}{l}\text { OUT } \\
\text { ATT } \\
\text {-IN ATT }\end{array}$ & $\begin{array}{l}\text { OUT CR } \\
\text {-IN CR }\end{array}$ & $\begin{array}{l}\text { OUT LE } \\
\text {-IN LE }\end{array}$ & $\begin{array}{l}\text { OUT IM } \\
\text {-IN IM }\end{array}$ \\
\hline \multirow[b]{2}{*}{$\begin{array}{l}20-30 \\
\text { years }\end{array}$} & $\mathrm{Z}$ & $-.412 \mathrm{a}$ & $-1.541 \mathrm{a}$ & $-1.473 a$ & $-1.276 \mathrm{a}$ & $-.843 a$ \\
\hline & $\begin{array}{l}\text { Asymptotic } \\
\text { significance } \\
\text { (double side) }\end{array}$ & .680 & .123 & .141 & .202 & .399 \\
\hline \multirow{2}{*}{$\begin{array}{l}31-39 \\
\text { years }\end{array}$} & $\mathrm{Z}$ & $-.719 a$ & $-1.290 \mathrm{~b}$ & $-1.973 b$ & $-.820 \mathrm{~b}$ & $-.938 \mathrm{a}$ \\
\hline & $\begin{array}{l}\text { Asymptotic } \\
\text { significance }\end{array}$ & .472 & .197 & .048 & .412 & .348 \\
\hline \multirow{2}{*}{$\begin{array}{l}40-50 \\
\text { years }\end{array}$} & Z & $.000 \mathrm{a}$ & $-.475 b$ & $-1.975 b$ & $-.119 b$ & $-.059 \mathrm{c}$ \\
\hline & $\begin{array}{l}\text { Asymptotic } \\
\text { significance }\end{array}$ & 1.000 & .635 & .048 & .905 & .953 \\
\hline
\end{tabular}

The data analysis showed no significant differences in the professional mentality rapid tests results before and after the five test scores for the 9 areas among age 30 and under driver groups in the EMU drivers of the Shenyang Railway Bureau. Their scores were slightly higher than the average ride back multiplied by the average score.

Table 11 Descriptive statistics for the Shenyang EMU drivers' professional psychological test results - ages 20 to 30

\begin{tabular}{lcccccc}
\hline Project & N & Minimum & Maximum & Mean & $\begin{array}{c}\text { Standard } \\
\text { Deviation }\end{array}$ & Variance \\
\hline IN ATT & 9 & 8.00 & 10.00 & 8.8889 & .78174 & .611 \\
OUT ATT & 9 & 6.00 & 10.00 & 8.4444 & 1.50923 & 2.278 \\
IN CR & 9 & 6.20 & 8.60 & 7.2889 & .98036 & .961 \\
OUT CR & 9 & 1.60 & 7.80 & 6.1778 & 1.86934 & 3.494 \\
IN LE & 9 & 7.00 & 12.00 & 9.6667 & 1.50000 & 2.250 \\
OUT LE & 9 & 6.00 & 11.00 & 8.8889 & 1.76383 & 3.111 \\
IN IM & 9 & 8.00 & 19.00 & 14.2222 & 3.38296 & 11.444 \\
OUT IM & 9 & 10.00 & 17.00 & 13.0000 & 2.29129 & 5.250 \\
IN VP & 9 & 2.80 & 9.20 & 6.6667 & 1.91311 & 3.660 \\
OUT VP & 9 & -1.00 & 8.80 & 5.7333 & 3.02324 & 9.140 \\
\hline
\end{tabular}

The results show that the 9 EMU Shenyang Railway Bureau drivers aged 30 or under had professional mentality scores, influenced by psychological load in a single continuous operation, that declined slightly. During four hours of operation, when they faced long and complex environments, there were traffic dispatchers to communicate, to record and to perform scheduling commands; hence, the slight decrease in the five tests' scores. The end result is that the Shenyang Railway Bureau's moderate mental load on drivers aged 30 or under, and the resulting overall labor intensity, do not significantly reduce mental fatigue among these drivers.

Table 12 Descriptive statistics for the Shenyang EMU drivers' professional psychological test results - ages 31 to 39

\begin{tabular}{lclllll}
\hline Project & N & Minimum & Maximum & Mean & $\begin{array}{l}\text { Standard } \\
\text { Deviation }\end{array}$ & Variance \\
\hline IN ATT & 15 & 3.00 & 9.00 & 7.8667 & 1.84391 & 3.400 \\
OUT ATT & 15 & 5.00 & 10.00 & 7.4000 & 1.40746 & 1.981 \\
IN CR & 15 & 2.20 & 8.00 & 5.8000 & 1.63881 & 2.686 \\
OUT CR & 15 & -7.20 & 7.40 & 4.3867 & 3.56608 & 12.717 \\
IN LE & 15 & 8.00 & 12.00 & 9.6000 & 1.24212 & 1.543 \\
OUT LE & 15 & 4.00 & 14.00 & 8.4000 & 2.26148 & 5.114 \\
IN IM & 15 & 8.00 & 19.00 & 13.8000 & 2.59670 & 6.743 \\
OUT IM & 15 & 10.00 & 19.00 & 13.6000 & 2.41424 & 5.829 \\
IN VP & 15 & 5.00 & 9.00 & 7.3600 & 1.36109 & 1.853 \\
OUT VP & 15 & 5.80 & 9.80 & 7.8667 & 1.31728 & 1.735 \\
\hline
\end{tabular}


The analysis results show that the professional psychological quality of the 15 drivers from the Shenyang Railway Bureau who were between 31 and 39 years old was affected by their psychological load and that their overall state declined significantly. In the course of driving for four hours, the drivers' attention allocation and transfers, complex reactions, instantaneous memory, and learning ability decreased. Their overall psychological load from the labor intensity was high, and their psychological load fatigue and their professional psychological quality decreased significantly.

Table 13 Descriptive statistics for the Shenyang EMU drivers' professional psychological test results - ages 40 to 50

\begin{tabular}{lclllll}
\hline Project & N & Minimum & Maximum & Mean & $\begin{array}{l}\text { Standard } \\
\text { Deviation }\end{array}$ & Variance \\
\hline IN ATT & 9 & 5.00 & 8.00 & 7.2222 & 1.09291 & 1.194 \\
OUT ATT & 9 & 5.00 & 9.00 & 7.1228 & 1.20185 & 1.444 \\
IN CR & 9 & 2.80 & 7.40 & 6.2222 & 1.39443 & 1.944 \\
OUT CR & 9 & -4.60 & 8.00 & 4.7778 & 4.32371 & 18.694 \\
IN LE & 9 & 7.00 & 11.00 & 8.8889 & 1.26930 & 1.611 \\
OUT LE & 9 & 4.00 & 10.00 & 7.2222 & 1.78730 & 3.194 \\
IN IM & 9 & 6.00 & 16.00 & 12.1111 & 2.97676 & 8.861 \\
OUT IM & 9 & 3.00 & 16.00 & 12.0000 & 3.74166 & 14.000 \\
IN VP & 9 & 4.20 & 8.40 & 7.0889 & 1.37518 & 1.891 \\
OUT VP & 9 & 3.60 & 9.40 & 6.8667 & 2.15639 & 4.650 \\
\hline
\end{tabular}

The results show that among the 15 EMU Shenyang Railway Bureau drivers who were aged 40 years and older, their professional mentality was influenced by the psychological load in a single continuous operation, but their overall state decreased significantly. In four hours of driving, attention allocation, transfer of complex reactions, instantaneous memory and learning ability declined, all of which gave the Shenyang Railway Bureau drivers who were older than age 40 years a high labor intensity based on psychological load strength testing.

Based on the analysis of psychological load labor intensity among EMU drivers, it was found that under the same operating conditions (a single driver working for four hours), drivers at all ages were affected by the mental load, based on the professional mentality rapid changes test results for the different age groups. It is clear that there were no significant differences. Among the group that was aged 30 years, there were significant changes, specifically, a significant decline in mean learning ability. Overall, the psychological burden on professional mentality exerted a greater impact on vocational psychological quality, and this decreased significantly, although to varying degrees. Overall, the labor-intensity-based mental load was lower for drivers at age 30 than it was for drivers who were below age 30 .

\section{Discussion}

Considering the effects of work time on the driver-based psychological burden of labor intensity, the Shenyang and Shanghai Railway Bureau EMU drivers showed more adverse effects from their typical operating times than did EMU drivers from the Beijing bureau, who drove $<2$ hours with no adverse effects on their professional psychological loads. In fact, the short driving times in the Beijing Railway Bureau might even have slightly enhanced the psychological load based on the low labor intensity. When single continuous operation time (i.e., the Shenyang and Shanghai Railway Bureau times of 4 hours) adversely affected mental load, and thus professional psychological quality, professional mental quality decreased to varying degrees.

Considering the locomotive drivers' driver-based psychological burdens and labor intensity, it is clear that the psychological load among the Shanghai Railway Bureau EMU drivers adversely affected their professional psychological quality.

Comparing two different sets of operating conditions, the Shenyang Railway Bureau posts single EMU drivers for four hours, whereas the Shanghai Railway Bureau has single drivers operating for 4-5 hours on average. Although the Shanghai Railway Bureau EMU drivers' average operating time is higher than that for the Shenyang drivers because of the double-driver system, the continuous operation time can be discretionary.

\section{Conclusions}

The purpose of this study was to investigate the existing, rational EMU driver allocations of human resources to maximize efficiency. Based on relevant theoretical research and drawing on that research on labor intensity using both domestic and foreign-based mental loads, and using the scientific method, we propose rational suggestions for EMU driver organization and management systems.

Based on the different operating times, this study compared the organization of different jobs in different situations. The negative impact of psychological load on EMU driver labor intensity varied. With a single-driver continuous value multiplied by a time of less than two hours, there were no significant differences; multiplied by more than 4 hours, there was a significant difference in psychological quality; specifically, the multiplied career mental quality level decreased significantly. The EMU single continuous value multiplied by driving time driver should not be more than four hours to receive the full benefit.

When EMU drivers average fewer than four hours of operating time, a two-crew operation system is necessary. Currently, China's EMU drivers face a reasonable workload; their overall labor intensity, that is, up to a certain psychological impact load, is within a reasonable range. EMU drivers' work organization not only reasonably addresses their work intensity but also attends to a reasonable mix of odd and even drivers.

Under the same operating conditions (one single driver working for four hours), the EMU drivers' ages, based on 
the clear effects for psychological load labor intensity, did to some extent influence mental load. Overall, the labor intensity impact for drivers aged 30 was less than that for drivers under age 30 years old driver. Regularly testing EMU team drivers, particularly those older than age 40 , should ensure road safety.

\section{Acknowledgements}

The study is supported by the Fundamental Research Funds for the Central Universities (No.2014JBZ006, No.2012YJS047).We appreciate the support very much.

\section{References}

Cabon, P., Coblentz, A., Mollard, R., Fouillot, P. (1993) Human Vigilance in Railway and Long-Haul Flight Operation. Ergonomics. 36(9), pp. 10191033. DOI: 10.1080/00140139308967974

Edkins, G. D., Pollock, C. M. (1997) The Influence of Sustained Attention on Railway Accidents. Accident Analysis \& Prevention. 29(4), pp. 533-539. DOI: 10.1016/S0001-4575(97)00033-X

Flemisch, F. O., Onken, R. (2002) Open a Window to the Cognitive Work Process! Pointillist Analysis of Man-Machine Interaction. Cognition, Technology \& Work. 4(3), pp. 160-170. DOI: 10.1007/s101110200015

Gašparík, J., Abramović, B., Halás, M. (2015) New Graphical Approach to Railway Infrastructure Capacity Analysis. PROMET-Traffic\& Transportation. 27(4), pp. 283-290. DOI: 10.7307/ptt.v27i4.1701

Kecklund, G., Akerstedt, T., Ingre, M., Soderstrom, M. (1999) Train Driver's Working Conditions and Their Impact on Safety, Stress and Sleepiness: A Literature Review, Analyses of Accidents and Schedules. Stress Research Report no 288, National Institute for Psychosocial Factors and Health (IPM), Department of Public Health Sciences, Division for Psychosocial Factors and Health, Karolinska Institute, Stockholm. Translation of a Swedish report. URL: https:/it.uu.se/research/project/train/ papers/SRR288etapp1.pdf

Langner, R., Eickhoff, S. B. (2013) Sustaining Attention to Simple Tasks: A Meta-Analytic Review of the Neural Mechanisms of Vigilant Attention. Psychological Bulletin. 139(4), pp. 870-900. DOI: 10.1037/a0030694

Loft, S., Sanderson, P., Neal, A., Mooij, M. (2007) Modeling and Predicting Mental Workload in En Route Air Traffic Control: Critical Review and Broader Implications. Human Factors. 49 (3), pp. 376-399.
Mitler, M. M., Carskadon, M. A., Czeisler, C. A., Dement, W. C., Dinges, D. F., Graeber, R. C. (1988) Catastrophes, sleep, and public policy: consensus report. Sleep. 11(1), pp. 100-109. http://www.ncbi.nlm.nih.gov/pmc/articles/PMC2517096/

Parasuraman, R., Hancock, P. A. (2001) Adaptive Control of Mental Workload. In: Stress, Workload and Fatigue. Hancock, P. A., Desmond, P. A. (eds.), pp. 305-320. Lawrence Erlbaum Associates, Mahwah, New Jersey.

Sussman, D., Coplen, M. (2000) Fatigue and Alertness in the United States Railway Industry Part I: The Nature of the Problem. Transportation Research Part F: Traffic Psychology and Behaviour. 3(4), pp. 211-220. DOI: 10.1016/S1369-8478(01)00005-5

van Dormolen, M., Hertog, C. A. W. M., van Dijk, F. J. H., Kompier, M. A. J., Fortuin, R. (1990) The Quest for Interaction: Studies on Combined Exposure. International Archives of Occupational and Environmental Health. 62(4), pp. 279-287. DOI: 10.1007/BF00640834

van Veldhoven, M. J. P. M., Sluiter, J. K. (2009) Work-Related Recovery Opportunities: Testing Scale Properties and Validity in Relation to Health. International Archives of Occupational and Environmental Health. 82(9), pp. 1065-1075. DOI: 10.1007/s00420-009-0411-z

Vidulich, M. A., Tsang, P. S. (2006) Mental Workload and Situation Awareness. In: Handbook of Human Factors and Ergonomics. Salvendy, G. (ed.), pp. 243-268, Wiley, Hoboken, New Jersey.

Warm, J. S., Parasuraman, R., Matthews, G. (2008) Vigilance Requires Hard Mental Work and is Stressful. Human Factors. 50(3), pp. 433-441. DOI: $10.1518 / 001872008 X 312152$

Wickens, C. D., Tsang, P. (2014) Workload. In: Handbook of Human-Systems Integration. Durso, F. (ed.), American Psychological Association, Washington, DC.

Young, M. S., Brookhuis, K. A., Wickens, C. D., Hancock, P. A. (2015) State of science: mental workload in ergonomics. Ergonomics. 58(1), pp. 1-17. DOI: $10.1080 / 00140139.2014 .956151$

Zhou, H. (2010) Research on Effect of EMU driver's Operating Time on Professional Psychological Quality. Master Thesis of Beijing Jiaotong University, China. URL: http://www.dissertationtopic.net/doc/664394

Zoer, I., Sluiter, J. K., Frings-Dresen, M. H. (2014) Psychological work characteristics, psychological workload and associated psychological and cognitive requirements of train drivers. Ergonomics. 57(10), pp. 1473-1487. DOI: $10.1080 / 00140139.2014 .938130$ 